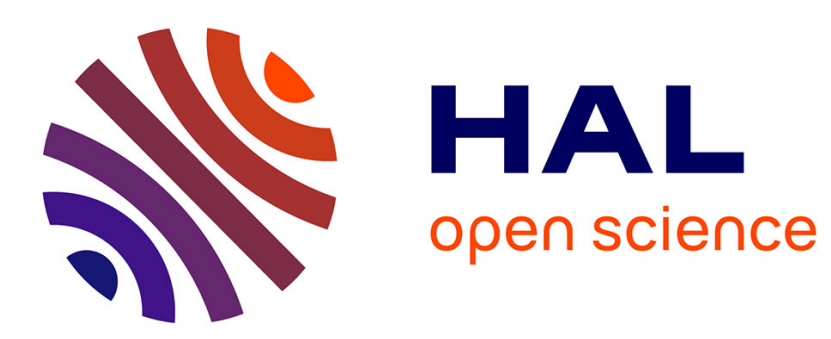

\title{
Specific heat at CDW transitions in bronzes
}

M. Chung, Y.-K. Kuo, G. Mozurkewich, E. Figueroa, Z. Teweldemedhin, D. Di Carlo, M. Greenblatt, J. Brill

\section{To cite this version:}

M. Chung, Y.-K. Kuo, G. Mozurkewich, E. Figueroa, Z. Teweldemedhin, et al.. Specific heat at CDW transitions in bronzes. Journal de Physique IV Proceedings, 1993, 03 (C2), pp.C2-247-C2-250. 10.1051/jp4:1993249 . jpa-00251332

\section{HAL Id: jpa-00251332 https://hal.science/jpa-00251332}

Submitted on 1 Jan 1993

HAL is a multi-disciplinary open access archive for the deposit and dissemination of scientific research documents, whether they are published or not. The documents may come from teaching and research institutions in France or abroad, or from public or private research centers.
L'archive ouverte pluridisciplinaire HAL, est destinée au dépôt et à la diffusion de documents scientifiques de niveau recherche, publiés ou non, émanant des établissements d'enseignement et de recherche français ou étrangers, des laboratoires publics ou privés. 


\title{
Specific heat at CDW transitions in bronzes
}

\author{
M. CHUNG, Y.-K. KUO, G. MOZURKEWICH*, E. FIGUEROA, Z. TEWELDEMEDHIN**, \\ D.A. DI CARLO ${ }^{* * *}$, M. GREENBLATT ${ }^{* *}$ and J.W. BRILL \\ Department of Physics and Astronomy, University of Kentucky, Lexington, KY 40506-0055, U.S.A. \\ * Research Laboratory, Ford Motor Company, Maildrop 3028, Dearbron, MI 48121, U.S.A. \\ ** Department of Chemistry, Rutgers, The State University of New Jersey, Piscataway, NJ 08855, U.S.A. \\ ${ }^{* * *}$ Laboratory of Atomic and Solid State Sciences, Cornell University, Ithaca, NY 14853, U.S.A.
}

\begin{abstract}
We have measured the specific heat of single crystals of $\mathrm{P}_{4} \mathrm{~W}_{8} \mathrm{O}_{32}, \mathrm{P}_{4} \mathrm{~W}_{12} \mathrm{O}_{44}$, and $\mathrm{K}_{0.3} \mathrm{MoO}_{3}$ at their CDW transitions. For $\mathrm{K}_{0.3} \mathrm{MoO}_{3}$, the anomaly is fit to a $3 \mathrm{~d}-\mathrm{XY}$ crossover model, and compared to the derivative of the susceptibility. For the phosphate tungsten bronzes, only the anomaly at the upper CDW transition in $\mathrm{P}_{4} \mathrm{~W}_{12} \mathrm{O}_{44}$ is resolved.
\end{abstract}

We have measured the heat capacity of single crystals of blue bronze $\left(\mathrm{K}_{0.3} \mathrm{MoO}_{3}\right)$ and the $\mathrm{m}=4$ and $\mathrm{m}=6$ layered phosphate tungsten bronzes (PTB), $\mathrm{P}_{4} \mathrm{~W}_{8} \mathrm{O}_{32}$ and $\mathrm{P}_{4} \mathrm{~W}_{12} \mathrm{O}_{44}$ respectively, at their charge-density-wave transitions using ac calorimetry [1-3]. Ac-calorimetry is an excellent technique for examining small crystals; in the past [1], the heat capacities of crystals as small as $10 \mu \mathrm{g}$ have been measured. In the present set of experiments, the crystal masses varied from $50 \mu \mathrm{g}$ to $2.5 \mathrm{mg}$. Although the relative precision of the technique is excellent, it does not yield values for the absolute value of the specific heat [3]; for blue bronze, these were found using differential scanning calorimetry [4]. A full description of our ac calorimeter is found in Reference 3. In the present paper, specific heats will be expressed in terms of the gas constant, $R=8.31 \mathrm{~J} / \mathrm{K}$ mole [transition metal].

We have previously reported a specific heat anomaly for the blue bronze of $0.15 R$ [2]. While this value is close to that reported by Konate [5], it is several times smaller than that obtained by Kwok et al from a comparison of the thermal conductivity and thermal diffusivity [6]. We therefore decided to compare results of crystals grown in different laboratories; in view of the previous divergence of results, special care was taken in choosing ac frequencies (typically $2 \mathrm{~Hz}$ ) to assure that the results were not compromised by finite thermal time constants. In Figure 1 are shown results for crystals prepared at the University of Kentucky (\#1) and Cornell University (\#2 and \#3). The results are similar for all three crystals, although for samples \#1 and \#2 structure in the peak presumably reflects some heterogeneity. In addition to the peak at the metal-insulator CDW transition $(180 \mathrm{~K})$, all three samples exhibit a small shoulder at $174 \mathrm{~K}$; the shoulder, which is much more obvious in plots of $c_{p} / T$ vs. $T$, is also present in the results of References 4 and 6, and may indicate a change in CDW order not reflected in the conductivity, 


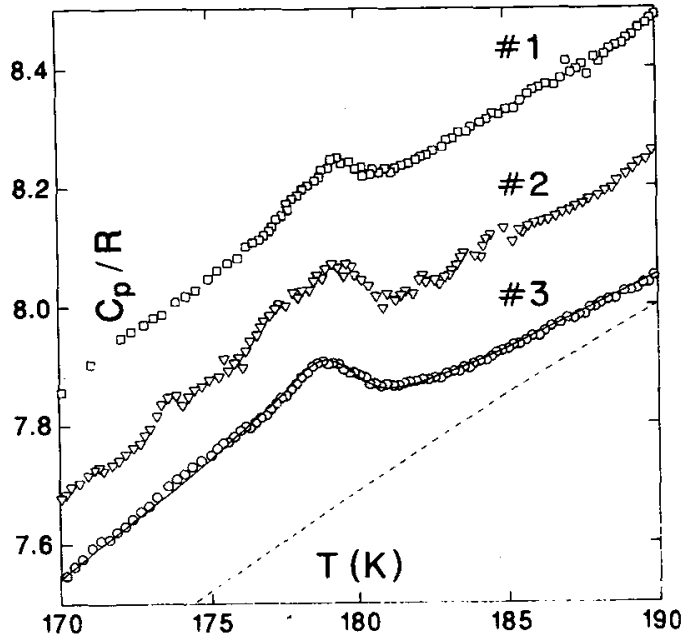

Figure 1 - Specific heat of blue bronze crystals near the 180K CDW transition. Data for crystals \#1 and \#2 have been vertically offset. The solid curve through the crystal \#3 data is the result of the crossover fit; the dashed curve is the polynomial background of this fit.

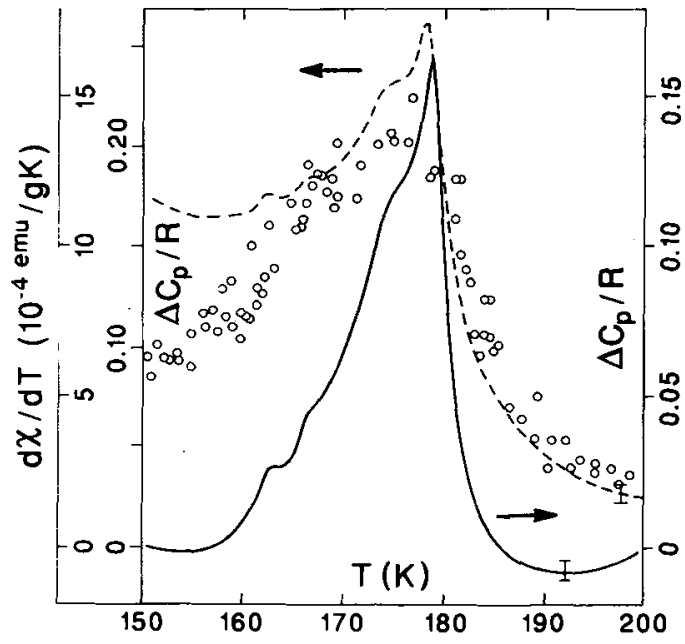

Figure $2-\mathrm{d} \chi / \mathrm{dT}$ (open circles) and $\Delta \mathrm{c}_{\mathrm{p}}$ (for crystal \#3) vs. temperature. The dashed curve is the measured data minus the background shown in Figure 1; the solid curve is the measured data minus a polynomial fit to the data for $\left|\mathrm{T}-\mathrm{T}_{\mathrm{c}}\right|>20 \mathrm{~K}$. Note that all three vertical axes have the same zero.

expansivity [7], etc. A plot of $\Delta c_{p}$ (i.e. the measured values minus a polynomial background fit to the data $20 \mathrm{~K}$ away from the transition) vs. temperature for crystal \#3 is shown in Figure 2.

The effects of fluctuations at the CDW transition on the thermal expansion coefficients [7] of blue bronze have been successfully fit by an expression [8] smoothly crossing over from mean-field far from $T_{c}$ to $3 d-X Y$ critical behavior near $T_{c}$. Furthermore, that fit, when compared to the measured pressure dependence of $T_{c}$, predicted a mean-field specific heat step of 0.17R [7], close to the value we measure. We have therefore done a similar fit for the measured specific heat of crystal \#3; the data (470 points between $140 \mathrm{~K}$ and $225 \mathrm{~K}$, smoothed over $1.2 \mathrm{~K}$ intervals) were fit to a polynomial plus crossover function [8], with resulting relative standard deviation $=7 \times 10^{-4}$. The fit is shown in Figure 1; the parameters of the critical "cusp" are $\overline{\mathrm{u}}=1.85$ and $\lambda=0.54$, reasonably close to the values obtained from the thermalexpansivity (2.6 and 0.6) [7]. The crossover region is a large fraction of $T_{c}$. The fit gives a mean-field contribution to the anomaly of $\Delta c_{p} / R=0.18$; this is a few times larger than the value obtained (4.7kT $T_{c} \Delta n$ ) from the density of states $(n=0.75$ states/eV mole [Mo]) calculated by Johnston [9], as expected for a one-dimensional system [2].

Kwok et al [6] also found that their specific heat anomaly scaled with the derivative of the 
susceptibility, $\Delta c_{p} \propto d \chi / d T$, as suggested by the model of Chandra [10], in which the susceptibility is coupled to lattice fluctuations. We make this comparison in Figure 2. The susceptibility was measured for a $50 \mathrm{mg}$ powdered sample using a Faraday balance; the derivative is similar to the published results [6,9]. If one simply defines $\Delta c_{p}$ as the measured values minus a polynomial backround (fit to the data slightly away from the transition [6]), the peak in $\Delta c_{p}$ is considerably sharper than that in $d \chi / d T$. However if $\Delta c_{p}$ is taken from the polynomial background of the cross over model, i.e. including a much wider fluctuation region, the agreement is good near and above $T_{c}$, i.e. where $\Delta c_{p}$ is dominated by fluctuations rather than its mean-field step. This result suggests that the fluctuations do involve lattice degrees of freedom, e.g. phasons, as expected.

The $\mathrm{m}=4$ and $\mathrm{m}=6$ PTB's each have two metal-metal CDW transitions $[11,12]$, near $50 \mathrm{~K}$ and $80 \mathrm{~K}$ $(\mathrm{m}=4)$ and $60 \mathrm{~K}$ and $120 \mathrm{~K}(\mathrm{~m}=6)$. As shown in Figure 3, no anomalies are seen at either $\mathrm{m}=4 \mathrm{CDW}$. transition $\left(\Delta c_{p}<0.2 \%\right.$ at $50 \mathrm{~K}$ and $\Delta c_{p}<0.5 \%$ at $\left.80 \mathrm{~K}\right)$ or the lower $\mathrm{m}=6\left(\Delta \mathrm{c}_{\mathrm{p}}<0.2 \%\right)$ transition. Near $120 \mathrm{~K}$, two anomalies are reproducibly observed for the $\mathrm{m}=6 \mathrm{PTB}$, a $0.35 \%$ change at $120 \mathrm{~K}$ and a $0.18 \%$ peak at 113K. (The data of Figures 3 and 4 have not been corrected for the contribution of addenda.) Note that only a single resistive anomaly has been observed near $120 \mathrm{~K}$ in the $\mathrm{m}=6$ PTB [11]; we have not yet

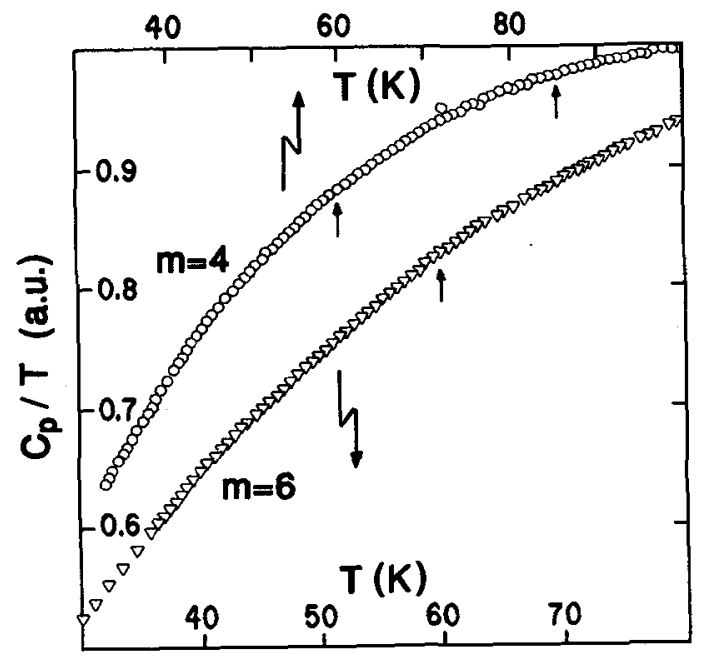

Figure 3 - Specific heat of $m=4$ and $m=6$ PTB crystals. The small vertical arrows show the locations of CDW transitions.

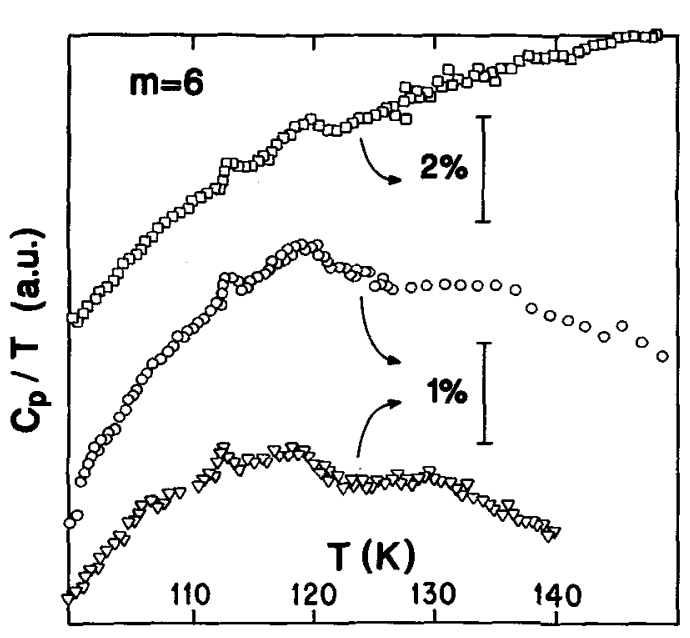

Figure 4 - Specific heats of three $m=6$ PTB crystals; values have not been corrected for addenda. 
determined to which thermal anomaly it is associated. An interesting possibility is that the lower peak is similar to the $174 \mathrm{~K}$ shoulder in blue bronze.

We have not normalized the specific heats, so will assume that they are approximately equal (per transition metal ion) to that of blue bronze. If we then use the mean-field equation, we find $\Delta \mathrm{n}<0.2$ states/eV mole [W] at the two lower transitions, $\Delta \mathrm{n}<0.6$ states $/ \mathrm{eV}$ mole [W] at $80 \mathrm{~K}(\mathrm{~m}=4)$ and $\Delta \mathrm{n} \sim 0.4$ states $/ \mathrm{eV}$ mole $[\mathrm{W}]$ at $120 \mathrm{~K}(\mathrm{~m}=6$, assuming $\Delta \mathrm{c} / \mathrm{c}=0.35 \%)$. That these values are all reasonable indicates that there are not large thermal fluctuation effects at these transitions. Although these materials are characterized as layered conductors [11], quasi-one dimensional bands have been calculated to be responsible for their transitions [13] and 1-D diffuse x-ray scattering has been observed near their transitions [12], so the lack of large fluctuations is surprising.

We are grateful to E. B. Kolomeisky and R.E. Thorne for useful conversations. This research has been supported in part by the U.S. National Science Foundation, Grants \#DMR-89-15440 and \#EHR-91-08764.

\section{References:}

[1] M. Chung, et al, Phys. Rev. B 45 (1992) 13831.

[2] M. Chung, et al, Synth. Met. 56 (1993) 2755.

[3] M. Chung, et al, submitted to Phys. Rev. B.

[4] Yiqin Wang, et al, Synth. Met. 46 (1992) 307.

[5] K. Konate, These de 3eme Cycle, Universite Scientifique, Technologique et Medicale de Grenoble, 1984.

[6] R.S. Kwok, G. Gruner, and S.E. Brown, Phys. Rev. Lett. 65 (1990) 365.

[7] M.R. Hauser, B.B. Plapp, and G. Mozurkewich, Phys. Rev. B 43 (1991) 8105.

[8] G. Mozurkewich, M.B. Salamon, and S.E. Inderhees, Phys. Rev. B 46 (1992) 11914.

[9] D.C. Johnston, Phys. Rev. Lett. 52 (1984) 2049.

[10] P. Chandra, J. Phys.: Condens. Matter 1 (1989) L3709.

[11] E. Wang, et al, Phys. Rev. B 39 (1989) 12969; Z.S. Teweldemedhin, K.V. Ramanujachary, and M. Greenblatt, Phys. Rev. B 46 (1992) 7897; M. Greenblatt, to be published in Reviews of Solid State Science.

[12] P. Foury, et al, Europhys. Lett. 16 (1991) 485; P. Foury and J.P. Pouget, to be published in Reviews of Solid State Science.

[13] E. Canadell and M.-Y. Whangbo, Phys. Rev. B 43 (1991) 1894. 